\title{
Marital Status, Smoking and Binge Drinking in Comparative Perspective $^{1}$
}

\author{
Dana Hamplová ${ }^{2}$ \\ Institute of Sociology of the Czech Academy of Sciences, Praha \\ Marital Status, Smoking and Binge Drinking in Comparative Perspective. The paper \\ explores cross-national differences in the link between marital status, smoking and binge \\ drinking. Using the International Social Survey Data (ISSP Health and Health Care) from \\ 2011, it tests whether the gap between married and single individuals depends on the \\ prevalence of the vice in the society. This hypothesis was partly corroborated for binge \\ drinking in both male and female samples though the link between marriage and alcohol \\ consumption is reversed in the high prevalence context. In case of smoking, the idea of the \\ decreasing role of marriage in countries where tobacco use is widespread was confirmed \\ only among men. The analysis also showed that cohabitation was not as strongly linked to \\ health practices as marriage. \\ Sociológia 2018, Vol. 50 (No. 6: 647-671) \\ https://doi.org/10.31577/sociologia.2018.50.6.24
}

Key words: Quality of life; marriage; smoking; alcohol; health behavior

Numerous studies from various disciplines demonstrate that married people have lower mortality and are healthier and happier than their unmarried counterparts, partly due to the healthier lifestyle. (Molloy et al. 2009; Yannakoulia et al. 2008; Duncan et al. 2006; Martikainen et al. 2005) The evidence that married individuals lead healthier lifestyle comes from various social contexts. Nevertheless, past research also suggests that the marriage lifestyle link varies across countries. For example, there is comprehensive evidence that married individuals are less likely to smoke and more likely to quit smoking in Scandinavia, the United States or South Korea but the Central and Eastern European countries with high smoking prevalence seem to be a notable exception. (Prady et al. 2012; Kalman et al. 2010; Cho et al. 2008; Nystedt 2006; Broms et al. 2004; Osler et al. 1999) Similarly, the link between marriage and alcohol intake also varies across countries. For example, the negative link was revealed in the United States or United Kingdom. (Ryan 2010; Staff et al. 2010; Collins et al. 2007; Duncan et al. 2006) Yet, some studies from Asia and France did not observe any association between marriage and drinking or even reported higher alcohol intake among the married population. (Park et al. 2008; Saito et al. 2005; Zins et al. 2003)

Despite the large cross-national variation, existing empirical research rarely uses comparative data or pays any attention to the cross-country differences in the marriage - health behavior link. A few exceptional studies using larger

\footnotetext{
${ }^{1}$ Work on this article was supported by grant from the Czech Science Foundation (GACR GB14-36154G).

2 Address: prof. PhDr. Dana Hamplová, Ph.D., Institute of Sociology of the Czech Academy of Sciences, Jilská 1, 11000 Praha 1, Czech Republic. E-mail: dana.hamplova@soc.cas.cz
} 
cross-national surveys focus mainly on comparison of specific sub-groups (e.g. Plant et al. 2008 compared married and cohabiting couples excluding singles). This paper aims to fill this gap in the literature by exploring the cross-national differences in the link between the current marital status and smoking and binge drinking. In particular, it explores the question of whether the gap between married and unmarried individuals systematically varies with the prevalence of the vice. The paper also outlines some possible theoretical explanation as to why this could be the case.

The article is organized as follows. First, it discusses the role of social control and selection in the marriage - lifestyle link. Afterwards, it argues that these processes might also explain as to why the size of the gap between married and unmarried individuals varies in different social contexts. Using the ISSP Health and Health Care 2011 data from 26 countries (International Social Survey Program - see ISSP Research Group 2015), the analytical part focuses on smoking and binge drinking as these practices are considered to be major causes of preventive death in the develop world. (Eikemo - Mackenbach 2012; Fenelon - Preston 2012; WHO 2011: 20) The empirical analysis is divided into two steps. First, the differences between married and single individuals are explored in all countries. Second, the analysis is expanded by including cohabiting individuals in countries where cohabitors constituted at least $5 \%$ of the sample.

Throughout the paper, we emphasize that the marriage - health behavior link is gendered and described mechanisms are likely to work differently in the male and female populations. Thus, all models are estimated separately for men and women.

\section{Marital status, social control, gender and health-enhancing behavior}

Nearly three decades ago, Debra Umberson published her seminal work linking the health advantage of currently married individuals to social control exercised in marriage. (Umberson 1992, 1987) She suggested that marriage promotes social integration through control of health practices as spouses encourage each other to engage in conventional and low-risk behavior. Though some type of social control is an integral part of all social relationships, the closer the relationship is, the more regulation is usually involved. (Lewis et al. 2006) Therefore, the social control is particularly pronounced in conjugal interactions and marriage is often viewed as the most consequential social relationship that affects health "through interpersonal interactions that involve influence, regulation, and constraint of health practices". (Lewis - Butterfield 2007: 299)

In this sense, social control is viewed as a general mechanism by which individuals and social groups or communities try to inhibit undesirable behavior, either by sanctions or by encouragement. (Dijker - Koomen 2007) In 
this broader understanding, social control refers also to social support and encouragement to avoid or quit unhealthy habits. The direct social control refers to the explicit rewards for behaviors defined as desirable and sanctions for behaviors that are deemed undesirable, deviant, and health-damaging. (Westmaas et al. 2002; Umberson 1987) The indirect social control operates through internalization of a sense of obligation to fulfill one's social role and to abstain from conducts inappropriate for this role. (Colman et al. 2013)

The general social control model is gender neutral. Nevertheless, past research demonstrates that females are usually more successful in influencing their male partners' health behaviors than vice versa. (Westmaas et al. 2002) Women generally possess more knowledge about health-related issues and monitor their own health status more closely than men. When they get married their traditional nurturing role encourage them not only to guard their own health but also to assume responsibility for their partners' behavior and monitor their spouses' health. (Umberson 1992) Indeed, married men report to have their behavior monitored more often than married women. (August - Sorkin 2010)

At the same time, women in general display stronger tendency to avoid risky behaviors and some of the risk aversion might spillover to their male partners. Furthermore, women seem to be more efficient in their ability to influence partners' health habits. A possible explanation is that women's social control efforts tend to incorporate higher emotional support. The ability to express sympathy and understanding might result in greater success in helping their spouses to quit unhealthy habits or to stick to the healthy routine. In contrast, men's attempts to control and influence unhealthy habits of their female partners might be viewed as inconsistent with their masculine roles and might produce negative reactions from their wives. (Westmaas et al. 2002)

\section{Marriage market, selection, and health behavior}

Social control is not the only mechanism explaining the lifestyle gap between married and unmarried individuals. Even though empirical studies suggest that causal processes (marriage affecting the behavior) are more important (Dinescu et al. 2016; Duncan et al. 2006; Power et al. 1999), some of the observed differences might be also attributed to the selection of individuals with certain characteristics into marriage. (Hamplová 2012; Collins et al. 2007; Wade Pevalin 2004; Chilcoat - Breslau 1996) Thus, individuals who engage in unhealthy behaviors such as excessive drinking or smoking might be viewed as less desirable partners. As a consequence, they are less likely to marry (or to stay married) and are found more often among the unmarried population.

Again, the selection process applies to both men and women. Nevertheless, the extent to which a vice affects individual's desirability as a partner is likely 
to vary in the male and female populations. For example, willingness to accept a partner with the vice might depend on perceived femininity or masculinity of the behavior or gender-specific tolerance for the activity. (Hunt et al. 2004)

It is necessary to emphasize that both selection and social control are not mutually exclusive but might have a reciprocal effect. In this paper, we do not attempt to disentangle their relative importance. Instead, we explore whether marriage - life style link varies with the vice prevalence and we argue that these two mechanisms might explain why it is the case.

\section{Smoking, binge drinking, and cross-national differences}

There are two reasons why cross-national differences in the association between marital status and health behavior might be linked to prevalence. First, as a consequence of the growing emphasis on the behavioral component of health, its controllability and personal responsibility in health protection, the beliefs regarding healthy lifestyle are increasingly assuming a normative character. At the same time, health compromising behavior has been growingly conceptualized as a form of deviance. (Dijker - Koomen 2007) Thus, healthpromotion interventions might have indirectly contributed to the production of social norms that equate 'unhealthy' and 'risky' with 'deviant'. (Peretti-Watel - Moatti 2006) Doing unhealthy things is a deviation from social norms and behavioral guidelines prescribing the active and responsible approach to one's health. Moreover, such behavior might be viewed as deviant because it threatens the (inclusive) fitness or reproductive success of genetically related group members. (Dijker - Koomen 2007: 16) As a deviation from the social norm of responsible approach to one's health, unhealthy lifestyle is likely to attract both the direct and indirect social sanctions.

Second, the degree of deviance might also deter union formation as smokers and binge drinkers might be considered less desirable partners. Nevertheless, though both activities might be viewed as deviant and might provoke some regulatory efforts the relative degree of their deviance is likely to differ across social contexts. By definition, the deviance is a departure from being normal and behavior that is quite common can hardly be considered highly deviant. Indeed, as past research shows, individuals give greater weight to social consequences if health risk behavior is less common. (Blanton - Christie 2003)

Thus, it is plausible to expect that the degree of deviance and corresponding social sanctions or selection effects are partly linked to the prevalence of this behavior in the society. In other words, if some undesirable behavior (e.g. smoking) is relatively common it is likely to be linked to less stigmatization and lower social sanctions. As a consequence, the effort to discourage others from engaging in it might be weaker or might be even perceived as illegitimate. In some cases, engaging in such behavior (e.g. smoking) might even be a 
means of procuring social acceptance. (DeWall - Pond 2011) At the same time, a common behavior is less likely to significantly worsen individual's desirability on the marriage markets as many potential partners engage in the same vice.

The argument that marriage is the institution that regulates health practices and that the degree of deviance is associated with the prevalence of the behavior implies that the gap between married and unmarried individuals should be smaller if the prevalence of behavior is higher. In other words, if marital status affects health behavior via social control and selection and if social control and selection are more stringent for less common behaviors, the differences between the married and unmarried individuals should vary according to the prevalence of the given vice. Thus, as more common behavior is likely to be viewed as less deviant even those whose conducts are more closely monitored and regulated (i.e. married individuals) are more likely to engage in this activity.

Both of our measures (alcohol intake and smoking) seem to be good indicators to test this framework because their prevalence largely varies across societies. For example, smoking has arguably already achieved a stigmatized status in the United States (Stuber et al. 2008) whereas its prevalence and acceptance is still relatively high in many European countries. (Joossens - Raw 2014) The drinking cultures and patterns of alcohol consumption vary crossnationally even more than tolerance towards smoking. (WHO 2011) In some situations and social contexts, even heavy drinking might be socially acceptable. (Schomerus et al. 2011; Heath 2000)

\section{Health-enhancing behavior, marriage and cohabitation}

Any study on the cross-national differences concerning marital behaviors needs to control for the fact that the role of marriage varies across context. In many developed countries, marriage underwent the process of deinstitutionalization. (Cherlin 2004; Džambazovič - Šprocha 2017) Though many different indicators can be used to express the level of de-institutionalization of marriage, it is usually accompanied by raise in unmarried cohabitation and singleness. At the same time, if marriage is very common, only individuals with particularly unattractive features are likely to stay single. Thus, we expect that the link between marriage and health behavior is weaker in countries with lower prevalence of marriage.

Furthermore, we must consider the role of unmarried cohabitation. Though most existing studies focus on the difference between married and single individuals, the research on the link between health behavior and marital status has become more complicated by the emergence of non-marital cohabitation in recent decades. In principle, the outlined mechanisms explaining the gap 
between married individuals and singles should apply not only to marriage but also to cohabitation. Cohabitation should offer similar benefits as marriage because co-residence with an intimate partner implies some degree of social control irrespective of the legal marital status. This would suggest that cohabitation plays similar role to marriage in terms of lifestyle, particularly in societies where it is highly institutionalized.

Nevertheless, a growing empirical literature from the United States and Europe demonstrates that cohabitation is associated with heightened risk of heavy drinking and drug use despite its resemblance to marriage. (Li et al. 2010; Plant et al. 2008; Joutsenniemi et al. 2007; Caetano et al. 2006) Moreover, cohabitation might be associated with elevated risk of heavy drinking even in Scandinavia where it is common and highly institutionalized, particularly if the couple does not live with children. (Plant et al. 2008; Joutsenniemi et al. 2007)

There are several possible explanations of the observed differences between marriage and cohabitation. First, cohabiting couples tend to be less-traditional and more open to alternative lifestyles, which makes them more vulnerable to the risk of chemical substance abuse. (Plant et al. 2008) If cohabitors are more opened to non-normative behaviors, they might be also less likely to pressure their partners to reduce alcohol consumption or to quit smoking. Moreover, cohabitation is less institutionalized than marriage and norms and prescribed behaviors for cohabitors are not as well defined as for married couples. (Hamplová et al. 2014) This might imply that the role of unmarried partner might not be associated with the same degree of behavioral constraints as the role of a spouse or that monitoring partner's behavior is less acceptable in cohabitation than in marriage. As a consequence, cohabitation might not be as strongly linked to health practices as marriage.

To sum up, past research shows that it might be inappropriate to merge married and cohabiting individuals. Yet, any research on the marriage - health behavior gap cannot ignore the demographic changes of last decades. Thus, though it is not the main focus of this paper, we also considers the role of cohabitation and the cross-national variation in its linked to smoking and binge drinking.

\section{Data and method}

The ISSP Health and Health Care 2011 data (ISSP Research Group 2015) were used to explore the link between marital status and binge drinking/smoking. (Similarly Džambazovič - Gebery 2014) Taiwan is dropped from the analysis as more than $50 \%$ of values were missing in some of the lifestyle variables. The data from the United Kingdom and Denmark were not used as these 
countries did not clearly distinguish married and unmarried couples. Only men and women aged 25+ were used for the analysis.

Two sets of models were estimated. First, the analysis focused on the differences between married and single individuals in 26 countries (Australia, Belgium, Bulgaria, Chile, Croatia, the Czech Republic, Finland, France, Germany, Israel, Japan, Korea, Lithuania, the Netherlands, Norway, Philippines, Poland, Portugal, Russia, Slovakia, Slovenia, South Africa, Sweden, Switzerland, Turkey, and the United States). Cohabitors were dropped from this analysis. In total, there was information on 14,176 married and single men and on 18,118 married and single women. In the second step, countries where cohabitors constituted at least $5 \%$ of the sample were selected and cohabitors were included in the model. In total, 17 countries fulfilled the criterion (Australia, Belgium, Bulgaria, Chile, the Czech Republic, Finland, France, Germany, the Netherlands, Norway, Philippines, Portugal, Slovenia, South Africa, Sweden, Switzerland, and the United States). The number of cohabitors in the country samples ranged from 66 to 431 in total (from 23 to 191 in the male sample, from 41 to 264 in the female sample). We also tried to set stricter criteria but the number of countries dropped significantly and it was not possible to estimate the random effects in all models.

Dependent variables: Lifestyle measures

Smoking was recorded on a 7-point scale from "do not smoke and never did" to "smoke more than 40 cigarettes per day". Using this question, a binary measure was constructed. Variable Smoking distinguished those who currently smoke (1) versus all current non-smokers (0). This is in line with the current scholarship that usually compare those who smoke and those who do not smoke without distinguishing intensity of smoking. (Prady et al. 2012; Kalman et al. 2010; Cho et al. 2008; Nystedt 2006; Broms et al. 2004) Those who smoked in the past but quitted were included among non-smokers. This distinction is appropriate given the cross-sectional character of the data and the focus on the link between health behavior and current marital status.

Alcohol consumption was measured by the following question: "How often do you drink 4 or more alcoholic drinks on the same day?". Respondents were choosing from an answer on a 5-point scale (never, once a month or less often, several times a month, several times a week, daily). Though there is not agreement how to define binge drinking most studies use four drinks per occasion as a benchmark. For example, the World Health Organization (WHO 2011) defines 'heavy episodic drinking' as consuming at least 60 grams or more of pure alcohol on at least one occasion for both sexes (corresponding to four small glasses of wine, or four cans or bottles of beer or cider. (See WHO 2011) Centers for Disease Control and Prevention (CDC) describe binge 
drinking as having four or more drinks for women and five or more drinks for men (http://www.cdc.gov/alcohol/fact-sheets/binge-drinking.htm). There is also no agreement about what frequency of 'heavy episodic drinking' constitutes health risk. Many studies differentiate between those who engage in such behavior at least once a month and those who do so less frequently. (Naimi et al. 2013; Pajak et al. 2013; Miller et al. 2007; Zeigler et al. 2005) Others consider even lower frequency as a risk and measure any binge drinking episode in the last 6 or 12 months. (Cranford et al. 2006; Naimi et al. 2003; Weissenborn - Duka 2003) Still others define binge drinkers as those who engage in 'heavy episodic drinking' at least once a week. (Kokavec - Crowe 1999)

This study did not set any specific criterion to distinguish binge drinkers and others based on the frequency of drinking episodes. As the ISSP data merged the response "once a month" and "less often" into one group, it would not be possible to create the category "at least once a month", which is the most common practice. Thus, this paper used a linear measure of binge drinking where lower number indicated lower frequency. Given that the indicator of binge drinking had only 5 categories, all models were re-estimated using the mixed-effects logistic regression for ordered responses (meologit in Stata 14). As both methods produced similar results, only estimates from the linear regression are reported in the text.

Control and explanatory variables

Marital status was the main explanatory variable. In the first step, marital status differentiated those who were married (codes as 0 ) and single (coded as 1); cohabitors were dropped from the sample. In the next step, more detailed measure of marital status (never married, divorced, and widowed) was used to account for heterogeneity of the single population. Afterwards, countries with at least 5 percent of cohabitors in the sample were selected and the marital status variable distinguished three categories: marriage, cohabitation, and singleness (marriage $=0 / 1$, cohabitation $=0 / 1$; singles are used as a comparative category).

Other covariates included sex (male $=1$ ), age (continuous), education in years (continuous; categorical measures was tested but do not improve models), employment status (non-working - 0 hours, part-time working, i.e. < 40 hours a week, full-time working, i.e. $40+$ hours), and a presence of a minor child in the household (at least one minor child $=1$, otherwise 0 ).

The prevalence of behavior in the given society was expressed by the sexspecific proportion of those who participate in the activity. All respondents (i.e. married, single, and cohabiting) were used to calculate the measure. Specifically, the prevalence of smoking was calculated as the proportion of 
men and women aged 25+ with the value of 1 in the binary measure for smoking (ranging from 12.5 to 51.1 in the male sample and 3.1 to 36.3 in the female sample). The prevalence of drinking was calculated as the mean value of binge drinking variable (ranging from 1.33 to 2.67 among men and from 1.11 to 1.71 among women). The proportion of married/cohabiting individuals was calculated using all men/women aged $25+$.

\section{Method}

A set of multilevel mixed-effects (logistic) regressions with the dependent variables smoking and alcohol consumption was estimated (Stata 14 meqrlogit and mixed). These models treat respondents as nested within countries and account for the inter-dependence between the observations. Given the fact that the prevalence was closely linked to the country-specific intercepts, including both measures in the same model would be problematic. Thus, the intercept was suppressed in all estimated models. The interval within which $95 \%$ of random coefficients lie was calculated as Level-1 Coefficient $-1+$ 1.96*Random Effect. (For more see Rabe-Hesketh - Skrondal 2008: 160) The significance of the interaction effect is tested by the likelihood-ratio test and the BIC - Bayesian information criterion. (Raftery 1995)

\section{Results}

\section{Descriptive statistics}

Table 1 reports descriptive statistics of the analytical sample. Only men and women aged $25+$ were included in the analysis. The mean age of respondents was 51.4 years, $56.1 \%$ of respondents were women. In total, $66.5 \%$ of the male sample and $57.9 \%$ of female sample was married at the time of the survey. The highest proportion of married individuals was found in Turkey, Philippines, Korea, and Australia whereas the South Africans, Americans, Russians, and Chileans were the least likely to be married. The proportion of cohabitors ranged from less than $1 \%$ (e.g. in Japan, Korea, Croatia, Russia) to around $15 \%$ in Scandinavia.

Table 2 demonstrates large cross-country variation and gender differences in the prevalence of smoking and binge drinking. It also shows that the gap between married, single, and cohabiting individuals differed across countries. The highest proportion of smokers in the male sample was found in Central and Eastern Europe, Philippines, Turkey, and South Korea (over $40 \%$ ). In contrast, Australian and Swedish men were least likely to smoke. Yet, the same patterns were not observed in the female sample. Even though the levels of smoking were exceptionally high among men from Russia, Philippines (and South Korea), they were exceptionally low among women from these countries. As a consequence, the three above-mentioned countries had the largest gender gap 
in smoking (approximately 37 percent point). In contrast, in France, Norway, and Sweden, the gender gap in smoking was reversed but the difference between men and women is very small.

Table 2 also shows that married men were generally less likely to smoke than single men. This conclusion holds in 25 countries out of 26 though the differences were negligible in some cases. Slovenia was the only country where married men were more likely to smoke than singles but the gap was also small (2.1 percentage point). In contrast, the link between marital status and smoking was much less pronounced in the female sample. While married women were less likely to smoke than their single counterparts in 16 countries out of 26, the difference was close to zero or even negative in 10 countries.

As for cohabitors, no clear patterns were observed either in the male or in the female sample. In some social contexts, they resembled married couples, in others they behaved more like singles. It is noteworthy that cohabitation was particularly risky state in the United States and Bulgaria. In the former country, over half of cohabiting men and over $40 \%$ of cohabiting women smoked. In Bulgaria, nearly three quarters of cohabiting men and over $65 \%$ of cohabiting women smoked.

Furthermore, Table 2 shows the proportion of sample that drank four or more drinks at one occasion at least several times a month. Heavy episodic drinking was most common among Korean, Japanese, Dutch, Lithuanian, and Polish men (over $40 \%$ ). In the female sample, binge drinking was most common in Belgium, Australia, and the Netherlands, closely followed by Japan and Korea (over $15 \%$ of women drank four or more drinks at one occasion on monthly basis). In contrast, binge drinking was least common among Turkish and Israeli men and Portuguese, Slovak, Bulgarian, and Slovenian women.

The difference between married and single women with respect to binge drinking was relatively small. Among men, married individuals tend to consume less alcohol in general. Japan is an exception from this trend as Japanese married men drank more than singles (15.5 percentage point). Similar result has been found also in other data. (Saito et al. 2005) Interestingly, in the majority of countries, cohabitors had the highest alcohol intake and this finding applies to both men and women. However, we must note that cohabitors were on average younger and the descriptive statistics did not control for age. 
Table 1: Descriptive statistics for the analytical sample

\begin{tabular}{|c|c|c|c|c|c|c|c|c|c|c|c|c|c|c|}
\hline & \multicolumn{7}{|l|}{ Men } & \multicolumn{7}{|l|}{ Women } \\
\hline & \multicolumn{2}{|c|}{ Union \% (comp. single) } & \multirow{2}{*}{$\begin{array}{l}\text { Has kids } \\
\%\end{array}$} & \multicolumn{2}{|c|}{ Work \% (comp.0 hours) } & \multirow{2}{*}{$\begin{array}{l}\text { Age } \\
\text { Mean } \\
\end{array}$} & \multirow{2}{*}{$\begin{array}{l}\text { Educ. } \\
\text { Mean }\end{array}$} & \multicolumn{2}{|c|}{ Union \% (comp. single) } & \multirow{2}{*}{$\begin{array}{l}\text { Has kids } \\
\%\end{array}$} & \multicolumn{2}{|c|}{ Work \% (comp.0 hours) } & \multirow{2}{*}{$\begin{array}{l}\text { Age } \\
\text { Mean }\end{array}$} & \multirow{2}{*}{$\begin{array}{l}\text { Educ. } \\
\text { Mean }\end{array}$} \\
\hline & Married & Cohabitation & & $1-39$ & $40+$ & & & Married & Cohabitation & & $1-39$ & $40+$ & & \\
\hline Australia & 73.4 & 8.1 & 26.5 & 29.3 & 30.6 & 57.0 & 13.6 & 65.1 & 8.0 & 26.5 & 45.8 & 10.3 & 54.8 & 13.8 \\
\hline Belgium & 67.3 & 7.8 & 27.7 & 35.4 & 19.8 & 53.5 & 13.0 & 60.7 & 7.3 & 29.9 & 42.2 & 9.1 & 52.1 & 12.7 \\
\hline Bulgaria & 65.3 & 6.3 & 28.4 & 31.7 & 20.0 & 54.2 & 11.7 & 51.9 & 7.7 & 28.5 & 45.8 & 10.3 & 55.2 & 11.3 \\
\hline Chile & 52.1 & 11.2 & 41.0 & 12.1 & 58.6 & 50.3 & 10.4 & 46.7 & 8.7 & 52.8 & 11.0 & 23.9 & 51.0 & 9.9 \\
\hline Croatia & 60.6 & 0.3 & 18.0 & 34.7 & 18.0 & 49.4 & 11.9 & 59.3 & 0.2 & 26.3 & 39.4 & 11.5 & 49.6 & 11.9 \\
\hline Czech R. & 69.1 & 6.9 & 27.5 & 20.6 & 48.0 & 50.8 & 12.9 & 59.4 & 8.7 & 31.7 & 27.5 & 30.2 & 50.3 & 12.7 \\
\hline Finland & 57.7 & 16.7 & 29.0 & 39.6 & 23.3 & 50.0 & 13.3 & 55.6 & 13.2 & 28.0 & 51.2 & 11.2 & 50.7 & 14.2 \\
\hline France & 65.5 & 10.6 & 27.4 & 35.4 & 17.9 & 55.4 & 13.9 & 54.9 & 12.5 & 37.4 & 49.1 & 7.9 & 51.2 & 13.9 \\
\hline Germany & 61.0 & 13.7 & 24.9 & 28.4 & 32.0 & 52.4 & 12.5 & 61.5 & 7.5 & 27.2 & 43.2 & 10.5 & 52.9 & 12.2 \\
\hline Israel & 73.2 & 3.6 & 39.7 & 24.2 & 41.4 & 50.4 & 12.9 & 71.3 & 1.1 & 54.4 & 42.4 & 17.3 & 49.1 & 13.2 \\
\hline Japan & 74.4 & 0.4 & 30.5 & 24.2 & 50.4 & 53.6 & 13.1 & 70.2 & 0.7 & 32.4 & 36.0 & 14.6 & 54.3 & 12.4 \\
\hline Korea & 79.5 & 0.0 & 43.8 & 28.1 & 53.1 & 48.4 & 13.2 & 69.6 & 0.0 & 43.0 & 21.8 & 25.7 & 48.9 & 11.2 \\
\hline Lithuania & 67.8 & 1.6 & 24.9 & 29.8 & 23.0 & 51.4 & 12.2 & 47.5 & 2.2 & 29.2 & 37.0 & 12.3 & 52.1 & 12.8 \\
\hline Netherlands & 67.0 & 6.2 & 18.5 & 41.1 & 14.1 & 55.3 & 14.1 & 52.9 & 8.0 & 25.3 & 51.0 & 2.5 & 53.3 & 13.3 \\
\hline Norway & 62.7 & 14.6 & 31.6 & 37.0 & 37.2 & 51.6 & 13.5 & 59.6 & 14.7 & 34.5 & 51.3 & 19.2 & 50.0 & 13.6 \\
\hline Philippines & 79.4 & 8.4 & 78.3 & 29.1 & 45.4 & 46.0 & 8.8 & 68.7 & 8.9 & 75.5 & 18.7 & 23.0 & 46.1 & 8.6 \\
\hline Poland & 71.9 & 4.8 & 38.3 & 27.4 & 34.8 & 50.8 & 12.6 & 62.3 & 3.5 & 40.3 & 33.6 & 15.0 & 52.2 & 12.4 \\
\hline Portugal & 71.5 & 8.5 & 27.2 & 26.9 & 26.1 & 53.9 & 9.6 & 60.0 & 6.5 & 36.9 & 31.7 & 15.9 & 53.5 & 9.0 \\
\hline Russia & 62.0 & 0.0 & 25.0 & 34.9 & 22.9 & 51.0 & 12.2 & 44.6 & 0.0 & 31.4 & 29.8 & 12.7 & 53.8 & 12.1 \\
\hline Slovakia & 76.8 & 1.0 & 30.7 & 22.6 & 35.2 & 53.7 & 13.3 & 57.6 & 2.0 & 27.9 & 26.6 & 20.1 & 54.7 & 13.1 \\
\hline Slovenia & 70.8 & 0.9 & 30.4 & 35.0 & 23.4 & 51.7 & 12.4 & 65.6 & 0.0 & 28.5 & 31.5 & 12.0 & 56.3 & 11.8 \\
\hline S. Africa & 48.0 & 5.9 & 36.6 & 21.1 & 28.4 & 45.1 & 10.5 & 41.9 & 5.7 & 59.6 & 12.8 & 12.4 & 45.3 & 9.5 \\
\hline Sweden & 59.6 & 12.8 & 34.1 & 38.3 & 26.9 & 52.8 & 12.2 & 54.5 & 16.9 & 32.4 & 52.1 & 10.5 & 51.4 & 12.9 \\
\hline Switzerland & 69.3 & 7.0 & 29.6 & 16.2 & 56.8 & 52.4 & 13.7 & 60.6 & 8.7 & 32.5 & 36.8 & 16.3 & 52.4 & 12.4 \\
\hline Turkey & 79.1 & 1.3 & 41.5 & 18.5 & 30.8 & 47.4 & 7.9 & 82.2 & 0.8 & 58.6 & 3.7 & 4.8 & 43.8 & 6.0 \\
\hline USA & 54.0 & 8.5 & 32.0 & 31.6 & 33.6 & 51.2 & 13.8 & 42.6 & 9.3 & 36.9 & 36.8 & 16.1 & 51.6 & 13.7 \\
\hline
\end{tabular}

Source: ISSP Health and Health Care 2011, Individuals $25+, \mathrm{N}$ (country) $=26, \mathrm{~N}($ men $)=14,176, \mathrm{~N}($ women $)=18,118$ 
Table 2: Lifestyle differences by marital status

\begin{tabular}{|c|c|c|c|c|c|c|c|c|c|c|c|c|c|c|c|c|}
\hline & \multicolumn{8}{|c|}{ Smoking (\%) } & \multicolumn{8}{|c|}{ Binge* drinking several times per month (\%) } \\
\hline & \multicolumn{4}{|c|}{ Men } & \multicolumn{4}{|l|}{ Women } & \multicolumn{4}{|c|}{ Men } & \multicolumn{4}{|l|}{ Women } \\
\hline & Married & Cohabiting & Single & Total & Married & Cohabit & Single & Total & Married & Cohabit & Single & Total & Married & Cohabit & Single & Total \\
\hline Australia & 9.8 & 13.3 & 22.1 & 12.3 & 4.5 & 14.7 & 15.0 & 8.2 & 34.8 & 52.5 & 35.5 & 36.4 & 16.7 & 30.9 & 14.4 & 17.2 \\
\hline Belgium & 16.3 & 36.4 & 25.6 & 20.2 & 12.9 & 16.9 & 24.1 & 16.8 & 35.7 & 46.8 & 36.8 & 36.9 & 15.9 & 22.5 & 20.8 & 17.9 \\
\hline Bulgaria & 42.3 & 73.9 & 43.3 & 44.5 & 28.7 & 65.9 & 23.4 & 29.4 & 12.6 & 13.0 & 23.1 & 15.6 & 2.6 & 2.4 & 2.8 & 2.7 \\
\hline Chile & 27.8 & 34.0 & 37.3 & 32.0 & 22.9 & 45.5 & 28.3 & 27.3 & 12.5 & 17.0 & 25.0 & 17.6 & 6.2 & 3.0 & 5.0 & 5.4 \\
\hline Croatia & 35.6 & $\mathrm{~N}<20$ & 48.6 & 41.0 & 36.1 & $\mathrm{~N}<20$ & 35.7 & 35.9 & 23.6 & $\mathrm{~N}<20$ & 32.9 & 27.2 & 9.7 & $\mathrm{~N}<20$ & 14.0 & 11.4 \\
\hline Czech R. & 42.7 & 52.3 & 51.0 & 45.3 & 24.8 & 35.6 & 20.0 & 24.2 & 26.7 & 52.3 & 36.2 & 30.7 & 8.2 & 21.9 & 12.2 & 10.7 \\
\hline Finland & 17.0 & 34.6 & 30.3 & 23.4 & 14.1 & 24.3 & 28.2 & 19.8 & 38.7 & 33.8 & 37.2 & 37.5 & 12.1 & 15.8 & 14.8 & 13.4 \\
\hline France & 16.3 & 33.3 & 35.8 & 22.8 & 18.2 & 40.1 & 26.0 & 23.5 & 27.2 & 27.7 & 37.9 & 29.8 & 8.0 & 13.9 & 10.0 & 9.4 \\
\hline Germany & 21.8 & 49.0 & 44.1 & 31.1 & 22.2 & 36.5 & 32.7 & 26.5 & 24.4 & 27.8 & 29.3 & 26.1 & 9.5 & 5.7 & 10.6 & 9.5 \\
\hline Israel & 26.6 & $\mathrm{~N}<20$ & 44.3 & 32.2 & 16.1 & $\mathrm{~N}<20$ & 24.7 & 18.3 & 10.6 & $\mathrm{~N}<20$ & 19.8 & 13.3 & 2.5 & $\mathrm{~N}<20$ & 8.9 & 4.2 \\
\hline Japan & 31.0 & $\mathrm{~N}<20$ & 40.8 & 33.5 & 11.4 & $\mathrm{~N}<20$ & 14.6 & 12.4 & 46.3 & $\mathrm{~N}<20$ & 30.8 & 42.2 & 14.4 & $\mathrm{~N}<20$ & 19.9 & 16.3 \\
\hline Korea & 37.9 & $\mathrm{~N}<20$ & 57.9 & 42.0 & 1.4 & $\mathrm{~N}<20$ & 7.1 & 3.1 & 57.0 & $\mathrm{~N}<20$ & 57.0 & 57.0 & 16.8 & $\mathrm{~N}<20$ & 15.0 & 16.3 \\
\hline Lithuania & 42.4 & $\mathrm{~N}<20$ & 47.9 & 44.2 & 13.0 & $\mathrm{~N}<20$ & 13.9 & 13.5 & 37.6 & $\mathrm{~N}<20$ & 46.4 & 40.5 & 11.2 & $\mathrm{~N}<20$ & 12.5 & 11.8 \\
\hline Netherlands & 17.9 & 6.3 & 26.5 & 19.5 & 12.1 & 18.4 & 25.6 & 17.9 & 38.3 & 62.5 & 41.6 & 40.7 & 15.8 & 12.0 & 19.8 & 17.0 \\
\hline Norway & 14.6 & 20.0 & 28.5 & 18.5 & 17.4 & 16.5 & 25.8 & 19.4 & 27.3 & 40.4 & 37.0 & 31.4 & 10.9 & 20.2 & 16.5 & 13.7 \\
\hline Philippines & 46.0 & 60.5 & 46.0 & 47.2 & 10.1 & 15.6 & 9.5 & 10.5 & 36.4 & 51.2 & 33.3 & 37.2 & 14.2 & 9.1 & 11.6 & 13.2 \\
\hline Poland & 30.6 & 55.0 & 34.7 & 32.7 & 18.1 & $\mathrm{~N}<20$ & 17.9 & 19.4 & 39.0 & 50.0 & 42.7 & 40.4 & 9.9 & $\mathrm{~N}<20$ & 9.8 & 10.4 \\
\hline Portugal & 23.9 & 50.0 & 40.5 & 29.4 & 13.8 & 28.6 & 20.3 & 17.0 & 19.1 & 15.6 & 28.0 & 20.6 & 1.2 & 2.9 & 1.1 & 1.3 \\
\hline Russia & 47.7 & $\mathrm{~N}<20$ & 52.1 & 49.3 & 12.8 & $\mathrm{~N}<20$ & 12.1 & 12.4 & 34.5 & $\mathrm{~N}<20$ & 33.6 & 34.1 & 7.1 & $\mathrm{~N}<20$ & 8.4 & 7.8 \\
\hline Slovakia & 29.5 & $\mathrm{~N}<20$ & 36.1 & 30.9 & 18.1 & $\mathrm{~N}<20$ & 13.8 & 16.9 & 17.9 & $\mathrm{~N}<20$ & 26.9 & 20.2 & 2.3 & $\mathrm{~N}<20$ & 0.0 & 1.5 \\
\hline Slovenia & 24.0 & $\mathrm{~N}<20$ & 22.0 & 23.9 & 15.0 & $\mathrm{~N}<20$ & 22.3 & 17.5 & 16.6 & $\mathrm{~N}<20$ & 15.2 & 16.0 & 1.1 & $\mathrm{~N}<20$ & 2.1 & 1.5 \\
\hline S. Africa & 30.5 & 41.2 & 33.0 & 32.3 & 11.8 & 19.4 & 12.7 & 12.7 & 21.0 & 50.0 & 33.7 & 28.5 & 10.7 & 24.3 & 9.8 & 11.0 \\
\hline Sweden & 8.3 & 11.3 & 19.5 & 11.8 & 10.1 & 14.7 & 16.9 & 12.8 & 27.0 & 35.8 & 35.4 & 30.5 & 10.1 & 13.0 & 16.9 & 12.5 \\
\hline Switzerland & 19.0 & 37.8 & 37.1 & 24.6 & 14.0 & 29.5 & 18.6 & 16.7 & 25.3 & 32.4 & 35.7 & 28.3 & 11.4 & 13.6 & 12.2 & 11.8 \\
\hline Turkey & 42.5 & $\mathrm{~N}<20$ & 56.0 & 45.2 & 17.9 & $\mathrm{~N}<20$ & 16.9 & 17.8 & 6.0 & $\mathrm{~N}<20$ & 17.6 & 8.2 & 3.4 & $\mathrm{~N}<20$ & 2.4 & 3.2 \\
\hline USA & 15.2 & 51.9 & 32.1 & 24.6 & 14.7 & 41.3 & 25.8 & 22.5 & 22.6 & 35.8 & 33.5 & 27.8 & 6.7 & 18.4 & 11.1 & 9.9 \\
\hline
\end{tabular}

Source: ISSP Health and Health Care 2011, Individuals 25+; * Binge drinking defined as having 4 or more alcoholic drinks on the same day. 
Multilevel Results I: Married and single individuals in 26 countries

Tables $3 \& 4$ bring estimated coefficients from the multilevel mixed effects regression with the dependent variable Smoker and Drinking. First, we raise the question of whether the gap between married and unmarried individuals was linked the proportion of married individuals in the country. Afterwards the effect of the prevalence of smoking/binge drinking was explored.

Models 1 and 2 show the overall differences between married and single individuals with respect to binge drinking and smoking, controlling for their age, education, economic activity, and presence of minor children in the household. As predicted, married men and women were less likely to smoke than single individuals. Single men and women had approximately 40-50\% higher odds of being a smoker than their married counterparts (see M1 in Table 3 ; $\exp (0.355)=1.42$ for men, $\exp (0.390)=1.47$ for women $)$. Nevertheless, Table 3 also suggests that the strength of the association between singleness and smoking varied across countries. The estimated coefficient for being single from M1 ranged from 0.255 to 0.454 among men and from 0.241 to 0.538 among women.

Models 2 in Table 3 tested the main hypothesis predicting that the association between marital status and health behavior was moderated by the prevalence of the vice. They included cross-level interactions between marital status and the prevalence of smoking. As Table 3 shows, the interaction term between smoking and prevalence was close to 0 in the female sample $(0.001)$. In contrast, the interaction effect was significant and negative in the male sample (-0.011). Thus, we can conclude that the gap between single and married men narrowed as smoking becomes more common. The trend was not negligible even from the substantive point of view. The odds ratio comparing single and married men varied from 1.8 in the low-prevalence context to 1.2 in the high-prevalence context. 
Table 3: Estimated regression coefficients from mixed effects logistic regression with dependent variable Smoking

\begin{tabular}{|c|c|c|c|c|c|c|c|c|c|c|c|c|}
\hline & Men & & & & & & Women & & & & & \\
\hline & M1 & M2 & M3 & M4 & M5 & M6 & M1 & M2 & M3 & M4 & M5 & M6 \\
\hline \multicolumn{13}{|l|}{ Individual level } \\
\hline Age & $-0.031^{* *}$ & $-0.031 * *$ & $-0.031 * *$ & $-0.031 * *$ & $-0.032 * *$ & $-0.031 * *$ & $-0.043^{* *}$ & $-0.043 * *$ & $-0.043 * *$ & $-0.043 * *$ & $-0.043 * *$ & $-0.043 * *$ \\
\hline Children in household & -0.063 & -0.070 & -0.076 & -0.074 & -0.082 & -0.078 & $-0.276^{* *}$ & $-0.276 * *$ & $-0.315 * *$ & $-0.314 * *$ & $-0.315^{* *}$ & $-0.317 * *$ \\
\hline \multicolumn{13}{|l|}{ Hours worked (0 comp.) } \\
\hline$<40$ per week & -0.055 & -0.064 & -0.071 & -0.069 & -0.076 & -0.073 & 0.092 & 0.093 & 0.056 & 0.057 & 0.056 & 0.055 \\
\hline $40+$ per week & 0.036 & 0.028 & 0.015 & 0.017 & 0.011 & 0.012 & $0.193 * *$ & $0.194 * *$ & $0.131 *$ & $0.131 *$ & $0.131 *$ & $0.129 *$ \\
\hline \multicolumn{13}{|l|}{ Marital status } \\
\hline Divorced & & & $0.811 * *$ & $0.664^{*}$ & $0.811^{* *}$ & 0.811 & & & $0.852 * *$ & $0.787 * *$ & $0.852 * *$ & $0.852 * *$ \\
\hline Widowed & & & -0.047 & -0.046 & -0.049 & 0.554 & & & 0.092 & 0.092 & 0.092 & 0.361 \\
\hline$\%$ of smokers & $0.043 * *$ & $0.033^{* *}$ & $0.043 * *$ & $0.043 * *$ & $0.044 * *$ & $0.044 * *$ & $0.060^{* *}$ & $0.060 * *$ & $0.062 * *$ & $0.062 * *$ & $0.062 * *$ & $0.063 * *$ \\
\hline Single (all)*\% of smokers & & $-0.011 *$ & & & & & & 0.001 & & & & \\
\hline Divorced*\% of smokers & & & & 0.005 & & & & & & 0.003 & & \\
\hline Never married $* \%$ of smokers & & & & & -0.011 & & & & & & 0.000 & \\
\hline Widowed $* \%$ of smokers & & & & & & -0.017 & & & & & & -0.014 \\
\hline Log likelihood & -7361.8 & -7360.0 & -7327.8 & -7327.7 & -7326.5 & -7326.8 & -7351.6 & -7351.6 & -7288.8 & -7288.8 & -7288.8 & -7288.5 \\
\hline
\end{tabular}

Source: ISSP Health and Health Care 2011, Individuals $25+, \mathrm{N}$ (country) $=26, \mathrm{~N}($ men $)=13,221 ; \mathrm{N}($ women $)=17,042$. 
As for alcohol consumption, the overall link between marriage and the frequency of binge drinking was also negative in both the male and female samples (M1 in Table 4). Nevertheless, the overall difference was relatively small. In general, being single shifts the estimated value by less than 0.10 on the 5-point scale. However, the estimated interval for $95 \%$ of random effects suggests that there were large differences across countries (from -0.177 to 0.324 among men; from -0.013 to 0.089 among women). This means that the association between marriage and binge drinking was even negative in some countries and married individuals were more likely to report heavy episodic drinking than their single counterparts. (Similarly Saito et al. 2005; Zins et al. 2003)

In case of binge drinking, the main hypothesis that the gap between married and single individuals depends on the prevalence of the behavior grows was corroborated for both men and women. BIC and the likelihood ratio test indicated that including the interaction term between prevalence and marital status significantly improved the overall fit of the model in male and female samples (BIC decreases from 38741.7 to 38729.5 among men and from 37884.3 to 37874.2 among women).

Nevertheless, closer inspection of the data suggest that there are some differences between men and women. The findings from the female sample fully corroborated the prediction about narrowing gap between married and single individuals in the high-prevalence contexts. In the low binge-drinking contexts, the estimated value ${ }^{3}$ for single and married women ranged from 1.152 (single) to 1.031 (married). In the countries with the highest prevalence of binge drinking, the difference in the estimated value for married and single individuals was negligible (1.69 versus. 1.72).

Though the trend looked similar for men, closer inspection of the data showed that the gap between married and single individuals narrowed only to some point. In the countries with the highest levels of binge drinking, the gap reversed and married men consumed more alcohol than singles. The estimated value for the frequency of binge drinking was 1.58 for single men and 1.21 for married men in the low binge-drinking contexts. Yet, in countries with the highest prevalence of binge drinking, the estimated value for married men (2.72) exceeded the estimated value for singles (2.52).

Models $1 \& 2$ in Tables $3 \& 4$ compared married and single individuals as a whole. Models 3 to 6 considered heterogeneity of the single population and distinguished between never married, single, and divorced individuals. Model 3 shows that widowed men and women did not significantly differ from their married counterparts in their tobacco consumption. In contrast, being divorced

3 To estimate the value, only drinking and marital status variables changes. Other variables were set to the mean. 
was the riskiest status for both men and women (see M3 in Table 3). Compared to their married counterparts, divorcees had more than two times higher odds of being smokers $(\exp (0.811)=2.25$ for men, $\exp (0.852)=2.34$ for women $)$. Never married individuals were somewhere in between married and divorced individuals and had approximately 25 percent higher odds of smoking $(\exp (0.201)=1.22$ for men, $\exp (0.229)=1.26$ for women $)$. As for binge drinking, the highest levels were found among divorced men and never married women (see M5 \& M9 in Table 3a \& 3b).

Model 4 indicated that as smoking prevalence grew the gap between single and married men narrowed. When different subgroups of singles were analyzed none of the coefficients reached statistical significance at the 0.01 level but the interaction between prevalence and never been married was marginally significant at the 0.10 level. As for drinking, the observed patterns were similar among all sub-groups of single men and the gap between them narrowed as excessive drinking became more common. Similarly to the results for men, alcohol consumption of single and married women became more similar in the high-prevalence context. However, Models $3-6$ revealed interesting differences among subgroups of singles. In general, never married women were most likely whereas married and widowed women were the least likely to binge drink (married and widowed women do not significantly differ). Thus, being never married is linked to a 0.101 shift on the 5-point scale of frequency of binge drinking. 
Table 4: Estimated regression coefficients from mixed effects regression with dependent variable frequency of Binge drinking*

\begin{tabular}{|c|c|c|c|c|c|c|c|c|c|c|c|c|}
\hline & \multicolumn{6}{|c|}{ Men } & \multicolumn{6}{|c|}{ Women } \\
\hline & M1 & M2 & M3 & M4 & M5 & M6 & M1 & M2 & M3 & M4 & M5 & M6 \\
\hline \multicolumn{13}{|l|}{ Individual level } \\
\hline Age & $-0.006 * *$ & $-0.006 * *$ & $-0.005 * *$ & $-0.005 * *$ & $-0.005 * *$ & $-0.005 * *$ & $-0.005 * *$ & $-0.006 * *$ & $-0.004 * *$ & $-0.004 * *$ & $-0.004 * *$ & $-0.005 * *$ \\
\hline Children in household & $-0.066^{* *}$ & $-0.071^{* *}$ & $-0.056^{*}$ & $-0.061^{* *}$ & -0.059 ** & $-0.059 * *$ & $-0.076^{* *}$ & $-0.088 * *$ & $-0.071^{* *}$ & $-0.072^{* *}$ & $-0.071^{* *}$ & $-0.075 * *$ \\
\hline Education in years & 0.001 & 0.001 & 0.001 & 0.001 & 0.001 & 0.001 & $0.004 * *$ & $0.003^{*}$ & 0.003 & 0.002 & 0.002 & 0.002 \\
\hline \multicolumn{13}{|l|}{ Hours worked (0 comp.) } \\
\hline$<40$ per week & $0.060^{*}$ & $0.053^{*}$ & $0.059 *$ & $0.053^{*}$ & $0.057^{*}$ & $0.057 *$ & $0.106 * *$ & $0.104 * *$ & $0.101 * *$ & $0.101 * *$ & $0.101 * *$ & $0.099 * *$ \\
\hline $40+$ per week & $0.104 * *$ & $0.094 * *$ & $0.103 * *$ & $0.096 * *$ & $0.098 * *$ & $0.100 * *$ & $0.171 * *$ & $0.165 * *$ & $0.165^{* * *}$ & $0.165 * *$ & $0.165 * *$ & $0.162 * *$ \\
\hline \multicolumn{13}{|l|}{ Marital status } \\
\hline Single & $0.073^{*}$ & $0.936^{* *}$ & & & & & $0.038^{* *}$ & $0.402 * *$ & & & & \\
\hline Never married & & & 0.074 & $0.895^{* * *}$ & 0.069 & 0.070 & & & $0.101 * *$ & 0.192 & $0.100 * *$ & $0.097 * *$ \\
\hline Divorced & & & $0.177 * *$ & $0.175^{* *}$ & $1.184 * *$ & $0.176 * *$ & & & $0.056^{*}$ & $0.056^{*}$ & 0.178 & $0.055^{*}$ \\
\hline Widowed & & & -0.040 & -0.039 & -0.039 & 0.625 & & & -0.040 & -0.039 & -0.039 & $0.601 * *$ \\
\hline Drinking (mean) & $1.109^{* *}$ & $1.128^{* *}$ & $1.090 * *$ & $1.107^{* *}$ & $1.100^{* *}$ & $1.097 * *$ & $1.115^{* *}$ & $1.145^{* *}$ & $1.096 * *$ & $1.099 * *$ & $1.099 * *$ & $1.110^{* *}$ \\
\hline Single*Drinking (mean) & & $-0.425 * *$ & & & & & & $-0.254^{* *}$ & & & & \\
\hline Divorced Drinking (mean) & & & & $-0.406^{* *}$ & & & & & & -0.063 & & \\
\hline Never mar* Drinking (mean) & & & & & -0.495 ** & & & & & & -0.084 & \\
\hline Widowed* Drinking (mean) & & & & & & $-0.328 *$ & & & & & & $-0.446 * *$ \\
\hline var (Single) & 0.128 & 0.057 & & & & & 0.026 & 0.000 & & & & \\
\hline $\operatorname{var}($ Nevermar) & & & 0.121 & 0.061 & 0.124 & 0.123 & & & 0.037 & 0.037 & 0.037 & 0.037 \\
\hline $\operatorname{var(\text {Divorced)}}$ & & & 0.132 & 0.134 & 0.098 & 0.133 & & & 0.074 & 0.073 & 0.075 & 0.074 \\
\hline $\operatorname{var}($ Widowed) & & & 0.107 & 0.111 & 0.110 & 0.053 & & & 0.081 & 0.081 & 0.025 & 0.081 \\
\hline BIC & 38741.7 & 38729.5 & 38770.0 & 38765.0 & 38769.7 & 38775.5 & 37884.3 & 37874.8 & 37886.2 & 37886.2 & 37868.5 & 37886.2 \\
\hline Log likelihood & -19328.1 & -19317.3 & -19323.3 & -19316.1 & -19318.4 & -19321.3 & -18898.3 & -18888.7 & -18875.0 & -18874.9 & -18866.1 & -18875.0 \\
\hline
\end{tabular}


Multilevel Results II: Married, cohabiting, and single individuals in 17 countries

In the next step, we selected countries where cohabitors constituted at least $5 \%$ of the sample $(\mathrm{N}=17)$ and re-estimated these models including both married and cohabiting individuals. The comparative category is being single (without distinguishing categories of singles). Table 5 reports two models. Model 1 included all control and explanatory variables and the prevalence of the vice in the given country. Model 2 added the cross-level interaction between the prevalence of the vice (smoking and binge drinking) and marriage and cohabitation.

Table 5 suggests that cohabitation was not linked to healthy lifestyle to the same extent as marriage. The link between smoking and marriage was systematically negative ( $95 \%$ of random coefficients for marriage are negative, i.e. between -0.483 and -0.439 for men; between -0.529 and -0.481 for women). In contrast, the corresponding intervals for cohabitation ranged from negative to positive (between -0.144 and 0.154 for men; between -0.155 and 0.077 for women). Thus, we can conclude that in all observed countries married individuals were less likely to smoke (controlled for their age, education, labor force participation, and presence of children in the household). However, we cannot make the same conclusion for cohabitors.

As for binge drinking, cohabiting men did not significantly differ from singles and the $95 \%$ of random coefficients for cohabitation ranged from 0.185 to 0.253 . Furthermore, cohabiting women were in a particularly high risk of heavy episodic drinking not only in comparison to their married but also their single counterparts (coefficient 0.095, significant at the 0.05 level). Nevertheless, we must emphasize that cohabiting unions were very heterogenous (and the sample was small). Thus, the $95 \%$ of random coefficients lie in a wide interval between -0.193 and 0.383 .

As for cross-level interactions between prevalence and cohabitation, the ISSP did not reveal any clear pattern. It is plausible to assume that the relative similarity between marriage and cohabitation in terms of lifestyle were not linked to the prevalence but other factors, such as institutionalization of cohabiting unions in the society. Moreover, our data did not allow us to distinguish between short-term and long-term cohabiting unions. Finally, it is necessary to note that the countries analyzed in the second step were not a representative sub-sample of those analyzed in the first step. It is reasonable to expect that in countries where cohabitation was common, marriage may not play the same role as it did in the more traditional countries. For example, it is plausible to expect that institutionalization of unmarried cohabitations was accompanied by de-institutionalization of marriage. (Cherlin 2004) As a 
consequence, the tendency to monitor partner's behavior might be weaker even in marriage in these countries.

Table 5: Estimated regression coefficients from mixed effects regressions with dependent variable Smoking and Frequency of binge drinking

\begin{tabular}{|c|c|c|c|c|c|c|c|c|}
\hline & \multicolumn{4}{|c|}{ Smoking } & \multicolumn{4}{|c|}{ Frequency of binge drinking } \\
\hline & \multicolumn{2}{|l|}{ Men } & \multicolumn{2}{|l|}{ Women } & \multicolumn{2}{|l|}{ Men } & \multicolumn{2}{|l|}{ Women } \\
\hline & M1 & M2 & M1 & M2 & M1 & M2 & M1 & M2 \\
\hline \multicolumn{9}{|l|}{ Individual level } \\
\hline Age & $-0.023 * *$ & $-0.021 * *$ & $-0.034 * *$ & $-0.031 * *$ & $-0.005^{* *}$ & $-0.005 * *$ & $-0.004 * *$ & $-0.005^{* *}$ \\
\hline Children in household & -0.028 & -0.022 & $-0.251 * *$ & $-0.214 * *$ & $-0.082 * *$ & $-0.081 * *$ & $-0.102 * *$ & $-0.112 * *$ \\
\hline Education in years & $-0.060 * *$ & $-0.053 * *$ & $-0.055 * *$ & $-0.049 * *$ & 0.000 & 0.000 & 0.003 & 0.002 \\
\hline \multicolumn{9}{|l|}{ Hours worked (0 comp.) } \\
\hline$<40$ per week & 0.063 & 0.089 & $0.116^{* *}$ & $0.144 * *$ & $0.068^{*}$ & $0.068 *$ & $0.097 * *$ & $0.092^{* *}$ \\
\hline $40+$ per week & 0.065 & 0.086 & 0.124 & $0.154^{*}$ & $0.114^{* *}$ & $0.116^{* *}$ & $0.148 * *$ & $0.140^{* *}$ \\
\hline \multicolumn{9}{|l|}{ Marital status (comp. single) } \\
\hline Married & $-0.461 * *$ & $-0.916 * *$ & $-0.505 * *$ & $-1.175^{* *}$ & $-0.109 * *$ & -0.091 & -0.011 & $0.335^{* *}$ \\
\hline Cohabitation & 0.005 & -0.535 & -0.039 & $-1.000 * *$ & 0.034 & -0.340 & $0.095^{*}$ & -0.023 \\
\hline \multicolumn{9}{|l|}{ Country level + interaction } \\
\hline$\%$ of smokers & $0.041 * *$ & $0.033^{* *}$ & $0.062 * *$ & $0.048 * *$ & 1.156 & 1.144 & $1.115^{* *}$ & $0.913^{* *}$ \\
\hline Married $* \%$ of smokers & & $0.016^{* *}$ & & $0.034 * *$ & & 0.009 & & $0.238^{* *}$ \\
\hline Cohabitation $* \%$ of smokers & & 0.020 & & $0.050 * *$ & & 0.184 & & 0.075 \\
\hline $\operatorname{var}($ Married) & 0.011 & 0.002 & 0.012 & 0.000 & 0.041 & 0.041 & 0.030 & 0.000 \\
\hline $\operatorname{var}($ Cohabiting) & 0.076 & 0.066 & 0.059 & 0.030 & 0.112 & 0.107 & 0.147 & 0.145 \\
\hline BIC & 11385.7 & 11392.7 & 12230.5 & 12228.4 & 30939.8 & 30957.5 & -14997.3 & -14989.2 \\
\hline Log likelihood & -5646.5 & -5640.7 & -6067.9 & -6057.3 & -15418.9 & -15418.5 & 30098.9 & 30101.7 \\
\hline
\end{tabular}

Source: ISSP Health and Health Care 2011, Individuals 25+, N (country) $=17, \mathrm{~N}($ men smoking) $=10,563$, $\mathrm{N}($ women smoking $)=13,104, \mathrm{~N}($ men drinking $)=10,578, \mathrm{~N}($ women drinking $)=13,061$

* Binge drinking defined as having 4 or more alcoholic drinks on the same day, frequency is measured on a

5-point scale from "never" to "daily"

\section{Conclusions}

Past research has demonstrated that married men and women are healthier and live longer than singles, which is often attributed to their healthier lifestyle. This article contributes to the ongoing debate by exploring cross-national differences in the marriage - health damaging behavior link (smoking, binge drinking). It raised the question of whether the prevalence of specific behavior in the broader social networks intervenes into the marriage - lifestyle link. It suggested that the concept of deviance might useful to explain the crossnational variation in the gap between married and single individuals.

Marriage is considered to be one of the most important social institutions in which health behavior is regulated and constrained. At the same time, individuals engaging in risky, unhealthy (and deviant) behavior might be 
perceived as less desirable partners on the marriage market and stay more often single (or divorce more often). Nevertheless, the intensity of regulatory efforts, the severity of sanctions and importance of marital selection are likely to depend on the perceived level of deviance. We argue that the level of perceived deviance and undesirability of the vice depends on its prevalence in the society. In other words, if everybody does it, it does not matter so much.

Thus, our explanatory framework is based on three assumptions. First, health-compromising behavior can be viewed as a form of deviance. Second, the perceived level of deviance depends on the prevalence of the vice. Third, marriage is the most important social relationships in which health behavior is sanctioned. These three assumptions imply that the differences between the married and unmarried individuals should vary according to the prevalence of the given vice. Specifically, the gap between married and unmarried should be smaller if the prevalence is higher.

Using the multilevel mixed effects regressions in Stata 14, the outlined theoretical framework was tested using the ISSP Health and Health Care 2011 data from 26 countries. Two measures were exploited in the analysis: smoking and binge drinking. The hypothesis that the gap between married and single individuals narrows as the vice becomes more common was corroborated only partly. As for binge drinking, the differences between married and single individuals were larger in low-prevalence context. However, the link between marriage and heavy episodic drinking reversed among men in the high prevalence context. As for smoking, the idea of the diminishing role of marriage in countries where this vice is more common was confirmed only among men. In contrast, single women were more likely to smoke irrespective of the prevalence of the vice among their peers.

Though the regulatory role of marriage with respect to smoking was found only among men, this study did not find major gender differences in terms of binge drinking. Single men and women are more likely to drink excessively but the gap between married and singles narrows in societies where binge drinking is more common.

The study also addressed the differences between marriage and cohabitation. Our data suggests that cohabitation is not as strongly linked to health practices as marriage. However, we need to exercise some caution as the samples were small. Moreover, cohabitors constitute very heterogeneous groups and our data did provided sufficient information to distinguish different type of unmarried co-residential unions.

Finally, we must also mention some limitations of this study. Above all, our study relies on the self-reported measures of smoking and binge drinking. Yet, it is likely that the willingness to admit such behavior might differ across societies. Unfortunately, our study - similarly to the existing scholarship - 
cannot control for the differences in the response styles. Moreover, it is necessary to emphasize that the ISSP Health and Health Care 2011 provide only limited number of covariates that could intervene into the marital status lifestyle link (e.g. comparative measure of income, union rank or duration). Furthermore, there is no information on the partnership quality or communication styles, which might affect the opportunity and ability to influence partner's behavior. The data also lacks a longitudinal perspective. We are not able to measure the development over time and we cannot distinguish between causal and selection mechanisms. Therefore, we cannot determine whether selection process into marriage differs across social contexts. Moreover, the survey does not provide any information on the partners' behaviors and we cannot account for the concordance within couples. (Meyler et al. 2007) Though marriage is usually considered to be an institution enhancing healthy lifestyle, it is also a place where people can engage in many vices. Individuals might discourage their partners from excessive drinking or smoking but they can be also tempted by such behavior.

Dana Hamplová is a senior scientist in the Institute of Sociology, Czech Academy of Sciences. Her research focuses on comparative research, social stratification, family behaviors, health, values, and religion. She authored or co-authored a number of books and her works are published in the top journal of the field such as Demography, Journal of Happiness Studies, Journal of Ethnic and Migration Studies. She is a member of various professional bodies. In 2018, she was elected to the board of the European Consortium for Sociological Research.

\section{REFERENCES}

AUGUST, K. J. - SORKIN, D. H., 2010: Marital Status and Gender Differences in Managing a Chronic Illness: The Function of Health-Related Social Control. Social Science and Medicine 71, pp. 1831-1838. doi:10.1016/j.socscimed.2010.08.022

BLANTON, H. - CHRISTIE, C., 2003: Deviance Regulation: A Theory of Action and Identity. Review of General Psychology 7, p. 115, doi: 10.1037/1089-2680.7.2.115

BROMS, U. - SILVENTOINEN, K. - LAHELMA, E. - KOSKENVUO, M. - KAPRIO, J., 2004: Smoking Cessation by Socioeconomic Status and Marital Status: The Contribution of Smoking Behavior and Family Background. Nicotine \& Tobacco Research 6, pp. 447-455, doi: 10.1080/14622200410001696637

CAETANO, R. - RAMISETTY-MIKLER, S. - FLOYD, L. R. - MCGRATH, C., 2006: The Epidemiology of Drinking Among Women of Childbearing Age. Alcoholism: Clinical and Experimental Research 30, pp. 1023-1030, doi: 10.1111/j.15300277.2006.00116.x

CHERLIN, A. J., 2004: The Deinstitutionalization of American Marriage. Journal of Marriage and Family 66, pp. 848-861, doi: 10.1111/j.0022-2445.2004.00058.x 
CHILCOAT, H. D. - BRESLAU, N., 1996: Alcohol Disorders in Young Adulthood: Effects of Transitions into Adult Roles. Journal of Health and Social Behavior 37, pp. 339-349, http://dx.doi.org/10.2307/2137261

CHO, H. J. - KHANG, Y. H. - JUN, H-J. - KAWACHI, I., 2008: Marital Status and Smoking in Korea: The Influence of Gender and Age. Social Science \& Medicine 66, pp. 609-619, doi: 10.1016/j.socscimed.2007.10.005

COLLINS, R. L. - ELLICKSON, P. L. - KLEIN, D. J., 2007: The Role of Substance use in Young Adult Divorce. Addiction 102, pp. 786-794, doi: 10.1111/j.13600443.2007.01803.x

COLMAN, E. - MISSINNE, S. - BRACKE, P., 2013: Mental Health Care use Among Recently Cohabiting and Newlywed Couples: An Application of the Social Control Theory. Social Work in Mental Health 12, pp. 132-154, doi: 10.1111/j.13600443.2007.01803.x

CRANFORD, J. A - MCCABE, S. E. - BOYD, C. J., 2006: A New Measure of Binge Drinking: Prevalence and Correlates in a Probability Sample of Undergraduates. Alcoholism: Clinical and Experimental Research 30, pp. 1896-1905, doi: 10.1111/j.1530-0277.2006.00234.x

DEWALL, C. N. - POND, R. S., 2011: Loneliness and Smoking: The Costs of the Desire to Reconnect. Self and Identity 10, pp. 375-385, doi: 10.1080/15298868.2010.524404.

DIJKER, A. J. M. - KOOMEN, W., 2007: Stigmatization, Tolerance and Repair. An Integrative Psychological Analysis of Responses to Deviance. Cambridge: Cambridge University Press, doi: 10.1017/CBO9780511489815

DINESCU, D. - TURKHEIMER, E. - BEAM, C. R. - HORN, E. E. - DUNCAN, G. EMERY, R. E., 2016: Is Marriage a Buzzkill? A Twin Study of Marital Status and Alcohol Consumption. Journal of Family Psychology 30, pp. 698-707, doi: $10.1037 /$ fam0000221

DUNCAN, G. - WILKERSON, B. - ENGLAND, P., 2006: Cleaning up their Act: The Effects of Marriage and Cohabitation on Licit and Illicit Drug use. Demography 43, pp. 691-710, doi: 10.1353/dem.2006.0032

DŽAMBAZOVIČ, R. - ŠPROCHA, B., 2017. Kto žije v kohabitáciách na Slovensku? Sociólogia 49, pp. 369-404.

DŽAMBAZOVIČ, R. - GERBERY, D., 2014. Sociálno-ekonomické nerovnosti v zdraví: sociálno-ekonomický status ako determinant zdravia. Sociólogia 46, pp. 194-219.

EIKEMO, T. A. - MACKENBACH, J., 2012: The Potential for Reducing Health Inequalities in Europe. EURO-GBD-SE Final Report. Rotterdam: Department of Public Health, University Medical Centre Rotterdam.

FENELON, A. - PRESTON, S. H., 2012: Estimating Smoking-Attributable Mortality in the United States. Demography 49, pp. 797-818, doi: 10.1007/s13524-012-0108-X

HAMPLOVÁ, D. - LE BOURDAIS, C. - LAPIERRE-ADAMCYK, E, 2014: Is the Cohabitation-Marriage Gap in Money Pooling Universal? Journal of Marriage and Family 76, pp. 983-997, doi: 10.1111/jomf.12138

HAMPLOVÁ, D., 2012: Zdraví a rodinný stav: dvě strany jedné mince? Sociologický časopis/Czech Sociological Review 48, pp. 735-755.

HEATH, D. B., 2000: Drinking Occasions: Comparative Perspectives on Alcohol and Culture. London: Routledge.

HUNT, K. - HANNAH, M. K. - WEST, P., 2004: Contextualizing Smoking: Masculinity, Femininity and Class Differences in Smoking in Men and Women from Three 
Generations in the West of Scotland. Health Education Research 19, pp. 239-249, doi: 10.1093/her/cyg061

ISSP Research Group, 2015: International Social Survey Programme: Health and Health Care - ISSP 2011. GESIS Data Archive, Cologne. ZA5800 Data file Version 3.0.0, doi:10.4232/1.12252.

JOOSSENS, L. - RAW, M., 2014: The Tobacco Control Scale 2013 in Europe. Brussels: Association of European Cancer Leagues.

JOUTSENNIEMI, K. - MARTELIN, T. - KESTILÄ, L. - MARTIKAINEN, P. PIRKOLA, S. - KOSKINEN, S., 2007: Living Arrangements, Heavy Drinking and Alcohol Dependence. Alcohol and Alcoholism 42, pp. 480-491, doi: 10.1093/alcalc/agm011

KALMAN, D. - HOSKINSON, R. - SAMBAMOORTHI, U. - GARVEY, A. J., 2010: A Prospective Study of Persistence in the Prediction of Smoking Cessation Outcome: Results from a Randomized Clinical Trial. Addictive Behaviors 35, pp. 179-182, doi: 10.1016/j.addbeh.2009.09.017

KOKAVEC, A. - CROWE, S. F., 1999: A Comparison of Cognitive Performance in Binge Versus Regular Chronic Alcohol Misusers. Alcohol and Alcoholism 34, pp. 601-608, doi: 10.1093/alcalc/34.4.601

LEWIS, M. A. - BUTTERFIELD, R. M., 2007: Social Control in Marital Relationships: Effect of One's Partner on Health Behaviors. Journal of Applied Social Psychology 37, pp. 298-319, doi: 10.1111/j.0021-9029.2007.00161.x

LEWIS, M. A. - MCBRIDE, C. M. - POLLAK, K. I. - PULEO, E. - BUTTERFIELD, R. M. - EMMONS, K. M., 2006: Understanding Health Behavior Change Among Couples: An Interdependence and Communal Coping Approach. Social Science \& Medicine 62, pp. 1369-1380, doi: 10.1016/j.socscimed.2005.08.006

LI, Q. - WILSNACK, R. - WILSNACK, S. - KRISTJANSON, A., 2010: Cohabitation, Gender, and Alcohol Consumption in 19 Countries: A Multilevel Analysis. Substance use \& misuse 45, pp. 2481-2502, doi: 10.3109/10826081003692106

MARTIKAINEN, P. - MARTELIN, T. - NIHTILÄ, E. - MAJAMAA, K. - KOSKINEN, S., 2005: Differences in Mortality by Marital Status in Finland from 1976 to 2000: Analyses of Changes in Marital-Status Distributions, Socio-demographic and Household Composition, and Cause of Death. Population Studies 59, pp. 99-115, doi: 10.1080/0032472052000332737

MEYLER, D. - STIMPSON, J. P. - PEEK, M. K., 2007: Health Concordance within Couples: A Systematic Review. Social Science \& Medicine 64, pp. 2297-2310, doi: 10.1016/j.socscimed.2007.02.007

MILLER, J. W. - NAIMI, T. S. - BREWER, R. D. - JONES, S. E., 2007: Binge Drinking and Associated Health Risk Behaviors Among High School Students. Pediatrics 119, pp. 76-85, doi: 10.1542/peds.2006-1517

MOLLOY, G. J. - STAMATAKIS, E. - RANDALL, G. - HAMER, M., 2009: Marital Status, Gender and Cardiovascular Mortality: Behavioural, Psychological Distress and Metabolic Explanations. Social science \& medicine 69, pp. 223-228, doi: 10.1016/j.socscimed.2009.05.010

NAIMI, T. S. - BREWER, R. D. - MOKDAD, A. - DENNY, C. - SERDULA, M. K. MARKS, J. S., 2003: Binge Drinking Among US Adults. JAMA: the journal of the American Medical Association 289, pp. 70-75, doi: 10.1001/jama.289.1.70

NAIMI, T. S. - XUAN, Z. - BROWN, D. W. - SAITZ, R., 2013: Confounding and Studies of 'Moderate' Alcohol Consumption: The Case of Drinking Frequency and Implications 
for Low-Risk Drinking Guidelines. Addiction 108, pp. 1534-1543, doi: 10.1111/j.13600443.2012.04074.x

NYSTEDT, P., 2006: Marital Life Course Events and Smoking Behaviour in Sweden 1980 - 2000. Social Science \& Medicine 62, pp. 1427-1442, doi: 10.1016/j.socscimed.2005.08.009

OSLER, M. - PRESCOTT, E. - GODTFREDSEN, N. - HEIN, H. O. - SCHNOHR, P., 1999: Gender and Determinants of Smoking Cessation: A Longitudinal Study. Preventive Medicine 29, pp. 57-62, doi: 10.1006/pmed.1999.0510

PAJAK, A. - SZAFRANIEC, K. - KUBINOVA, R. - MALYUTINA, S. - PEASEY, A. PIKHART, H. - NIKITIN, Y. - MARMOT, M. - BOBAK, M., 2013: Binge Drinking and Blood Pressure: Cross-Sectional Results of the HAPIEE Study. PLoS ONE 8:e65856, doi: 10.1371/journal.pone.0065856

PARK, J. T. - KIM, B. G. - JHUN, H. J., 2008: Alcohol Consumption and the CAGE Questionnaire in Korean Adults: Results from the Second Korea National Health and Nutrition Examination Survey. Journal of Korean medical science 23, pp. 199-206, doi: 10.3346/jkms.2008.23.2.199

PERETTI-WATEL, P. - MOATTI, J. P., 2006: Understanding Risk Behaviours: How the Sociology of Deviance May Contribute? The Case of Drug-Taking. Social Science \& Medicine 63, pp. 675-679, doi: 10.1016/j.socscimed.2006.01.029

PLANT, M. - MILLER, P. - PLANT, M. - KUNTSCHE, S. - GMEL, G. - AHLSTRÖM, S. - ALLAMANI, A. - BECK, F. - BERGMARK, K. - BLOOMFIELD, K., 2008: Marriage, Cohabitation and Alcohol Consumption in Young Adults: An International Exploration. Journal of Substance Use 13, pp. 83-98, doi: 10.1080/14659890701820028

POWER, C. - RODGERS, B. - HOPE, S., 1999: Heavy Alcohol Consumption and Marital Status: Disentangling the Relationship in a National Study of Young Adults. Addiction 94, pp. 1477-1487, doi: 10.1046/j.1360-0443.1999.941014774.x

PRADY, S. L. - KIERNAN, K. - BLOOR, K. - PICKETT, K., 2012: Do Risk Factors for Post-Partum Smoking Relapse Vary According to Marital Status? Maternal and Child Health Journal 16, pp. 1364-1373, doi: 10.1007/s10995-011-0899-1

RABE-HESKETH, S. - SKRONDAL, A., 2008: Multilevel and Longitudinal Modeling Using Stata. College Station: Stata Press.

RAFTERY, A., 1995: Bayesian Model Selection in Social Research. Sociological Methodology 25, pp. 111-163, doi: 10.2307/271063

RYAN, A. K., 2010: Gender Differences in Family Formation Behavior: The Effects of Adolescent Substance Use. Journal of studies on alcohol and drugs 71, pp. 938, doi: $10.15288 /$ jsad.2010.71.938

SAITO, I. - OKAMURA, T. - FUKUHARA, S. - TANAKA, T. - SUZUKAMO, Y. OKAYAMA, A. - UESHIMA, H., 2005: A Cross-Sectional Study of Alcohol Drinking and Health-Related Quality of Life Among Male Workers in Japan. Journal of occupational health 47, pp. 496-503, doi: 10.1539/joh.47.496

SCHOMERUS, G. - LUCHT, M. - HOLZINGER, A. - MATSCHINGER, H. - CARTA, M. G. - ANGERMEYER, M. C., 2011: The Stigma of Alcohol Dependence Compared with other Mental Disorders: A Review of Population Studies. Alcohol and Alcoholism 46, pp. 105-112, doi: 10.1093/alcalc/agq089

STAFF, J. - SCHULENBERG, J. E. - MASLOWSKY, J. - BACHMAN, J. G. O'MALLEY, P. M. - MAGGS, J. L. - JOHNSTON, L. D., 2010: Substance Use Changes and Social Role Transitions: Proximal Developmental Effects on Ongoing 
Trajectories from Late Adolescence Through Early Adulthood. Development and Psychopathology 22, pp. 917-932, doi: 10.1017/S0954579410000544

STUBER, J. - GALEA, S. - LINK, B. G., 2008: Smoking and the Emergence of a Stigmatized Social Status. Social Science \& Medicine 67, pp. 420-430, doi: 10.1016/j.socscimed.2008.03.010

UMBERSON, D., 1987: Family Status and Health Behaviors: Social Control as a Dimension of Social Integration. Journal of Health and Social Behavior 28, pp. 306-319, doi: $10.2307 / 2136848$

UMBERSON, D., 1992: Gender, Marital Status and the Social Control of Health Behavior. Social Science \& Medicine 34, pp. 907-917, doi: 10.1016/0277-9536(92)90259-S

WADE, T. J. - PEVALIN, D. J., 2004: Marital Transitions and Mental Health. Journal of Health and Social Behavior 45, pp. 155-170, doi: 10.1177/002214650404500203

WEISSENBORN, R. - DUKA, T., 2003: Acute Alcohol Effects on Cognitive Function in Social Drinkers: Their Relationship to Drinking Habits. Psychopharmacology 165, pp. 306-312, doi: 10.1007/s00213-002-1281-1

WESTMAAS, J. L. - WILD, T. C. - FERRENCE, R., 2002: Effects of Gender in Social Control of Smoking Cessation. Health Psychology 21, p. 368, http://dx.doi.org/10.1037/0278-6133.21.4.368

WHO, 2011: Global Status Report on Alcohol and Health. Geneva: WHO Press.

YANNAKOULIA, M. - PANAGIOTAKOS, D. - PITSAVOS, C. - SKOUMAS, Y. STAFANADIS, C., 2008: Eating Patterns May Mediate the Association Between Marital Status, Body Mass Index, and Blood Cholesterol Levels in Apparently Healthy Men and Women from the ATTICA Study. Social science \& medicine (1982) 66, pp. 2230-2239, doi: 10.1016/j.socscimed.2008.01.051

ZEIGLER, D. W. - WANG, C. C. - YOAST, R. A. - DICKINSON, B. D. MCCAFFREE, M. A. - ROBINOWITZ, C. B. - STERLING, M. L., 2005: The Neurocognitive Effects of Alcohol on Adolescents and College Students. Preventive Medicine 40, pp. 23-32, doi: 10.1016/j.ypmed.2004.04.044

ZINS, M. - GUEGUEN, A. - LECLERC, A. - GOLDBERG, M., 2003: Alcohol Consumption and Marital Status of French Women in the GAZEL Cohort: A Longitudinal Analysis Between 1992 and 1996. Journal of studies on alcohol and drugs 64, p. 784, doi: 10.15288/jsa.2003.64.784 